\title{
Factors associated with induced second trimester abortion at a tertiary level hospital of Uttarakhand region: a 6-year retrospective study
}

\author{
Shweta Nimonkar, Priyanka Chaudhari*, Vineeta Gupta, Namrata Saxena, Shivangi Agarwal
}

Department of Obstetrics and Gynecology, Shri Guru Ram Rai Institute of Medical and Health Sciences, Dehradun, Uttarakhand, India

Received: 31 March 2020

Accepted: 29 April 2020

*Correspondence:

Dr. Priyanka Chaudhari,

E-mail: dishitapriya07@gmail.com

Copyright: (c) the author(s), publisher and licensee Medip Academy. This is an open-access article distributed under the terms of the Creative Commons Attribution Non-Commercial License, which permits unrestricted non-commercial use, distribution, and reproduction in any medium, provided the original work is properly cited.

\section{ABSTRACT}

Background: Despite the liberalization of the abortion services since the early 1970s in India, access to safe abortion services remains limited for the vast majority of Indian women particularly from rural areas. Second trimester abortions have different indications and associated with increased maternal morbidity and mortality as compared to the first trimester abortions.

Methods: This study was a retrospective study conducted from the January 2014 to December 2019 at obstetrics and genecology department of Shri Guru Ram Rai Institute of Medical and Health Sciences, Dehradun, Uttarakhand, India. All patients of 12 weeks to 20 weeks of confirmed gestational age were given medical method of second trimester abortion. Data was collected and analyzed regarding demographic features, gestational age, indications, and induction-abortion interval and post abortion contraceptive methods accepted by patient.

Results: During this study period a total of 180 patients had second trimester abortion at study institute. Maximum number of patients $69(38.3 \%)$ were of 25-30 years of age group and $161(85 \%)$ patients were of Hindu religion. Major indication was failure of contraception (42.8\%) and congenital anomalies in the fetus (45.6\%). There was one case of failed medical abortion in which emergency hysterectomy was done for undiagnosed adherent placenta. All patients were compliant of using contraceptive methods after the abortion because of recent medical and mental stress and majority $82(45.6 \%)$ of the patients preferred oral combined contraceptive pills.

Conclusions: Apart from congenital anomalies rest all indications can be reduced if women in our country are empowered to control their fertility, get education to become more aware and provided with social security.

Keywords: Abortion, Induction, Medical abortion, Medical termination of pregnancy act, Second trimester

\section{INTRODUCTION}

There will always be women who need abortions after 12 weeks of pregnancy, and their reasons are often same as first trimester abortions and sometimes even more compelling. Although second trimester abortions carry relatively more risks than first trimester abortions, abortion is still very safe throughout the second trimester if done in safe conditions. Accessible and effective provision of second-trimester abortion is particularly important in settings where a high proportion of women seek abortion in the second trimester, as is common in our country. According to the first national study of the incidence of abortion and unintended pregnancy in India, an estimated 15.6 million abortions were performed in the country in $2015 .{ }^{1}$ This translates to an abortion rate of 47 per 1,000 women aged 15-49, which is similar to the abortion rate in neighbouring South Asian countries.

Authors did a retrospective study of all the second trimester abortions performed in our institute over a period of 6 years. The aim of the study was to determine the relevant factors associated with second trimester abortions with objectives to determine the demographic 
profile, parity, changing trends in reasons to seek for second trimester abortions, method of choice, and acceptability of contraception after abortions.

\section{METHODS}

This study was a retrospective study conducted from the January 2014 to December 2019 at obstetrics and genecology department of Shri Guru Ram Rai Institute of Medical and Health Sciences, Dehradun, Uttarakhand, India. Guidelines provided by Medical termination of pregnancy (MTP) act were strictly followed as routine in all cases. Data was collected regarding demographic features, gestational age, indications, and induction abortion interval and post abortion contraceptive method accepted by patient.

Second trimester included patients of 12 weeks of gestational age to 20 weeks of gestation and it must correspond to the gestational age confirmed by ultrasound and not merely on last menstrual period (LMP). In our institution, for all second trimester abortion medical method of induction was used by giving mifepristone $200 \mathrm{mg}$ orally followed by prostaglandin E1 (misoprostol) in doses of $400 \mathrm{mcg}$ vaginally and repeated every 4 hours to maximum of $2000 \mathrm{mcg}$. Success rate of abortion with this regimen is $97 \%-99 \%$ and median induction-abortion interval was 6.5 hours to 8.5 hours. Pre-treatment with mifepristone reduces the induction to abortion interval significantly compared to use of misoprostol alone.

\section{Inclusion criteria}

- All the patients who were admitted for second trimester induced abortion were included in the study.

\section{Exclusion criteria}

- Those patients who came for inevitable or incomplete second trimester abortion were excluded from the study.

The data was collected from patient's medical records and MTP register maintained in the department.

\section{RESULTS}

A total of 180 patients were admitted for second trimester induced abortions during the study period of 6 years from January 2014 to December 2019. In our study, Table 1 shows that maximum number of patients belonged to 25 30 years of age group $69(38.3 \%)$ followed by $20-25$ years of age group $39(21.7 \%)$. Patient less than 20 years who opted for second trimester abortions were $6(3.3 \%)$.

To analyse the religious outlook towards second trimester abortions, religion wise data was collected and tabulated. Hindus were 161 (85\%) followed by Muslims 16 (8.9\%).
There were (1.7\%) Sikh patients and others included Buddhist, Jain, and Tibetans (Table 2).

Table 1: Age wise distribution.

\begin{tabular}{|lll|}
\hline Age & $\mathbf{n = 1 8 0}$ & $\mathbf{\%}$ \\
\hline$<20$ & 06 & $3.33 \%$ \\
\hline$>20-25$ & 39 & $21.7 \%$ \\
\hline$>25-30$ & 69 & $38.3 \%$ \\
\hline$>30-35$ & 36 & $20 \%$ \\
\hline$>35$ & 30 & $16.7 \%$ \\
\hline
\end{tabular}

Table 2: Religion wise distribution.

\begin{tabular}{|lll|}
\hline Religion & $\mathbf{n = 1 8 0}$ & \% \\
\hline Hindu & 153 & $85 \%$ \\
\hline Muslim & 16 & $8.9 \%$ \\
\hline Catholic & - & - \\
\hline Sikh & 03 & $1.7 \%$ \\
\hline Others & 08 & $4.4 \%$ \\
\hline
\end{tabular}

Table 3: Marital status and parity.

\begin{tabular}{|lll|}
\hline Marital status & $\mathbf{n = 1 8 0}$ & $\mathbf{\%}$ \\
\hline Unmarried/single & 04 & $\mathbf{2 . 2 \%}$ \\
\hline Married & 176 & $97.7 \%$ \\
\hline Parity & & \\
\hline 0 & 48 & $26.7 \%$ \\
\hline 1 & 56 & $31.1 \%$ \\
\hline 2 & 55 & $30.6 \%$ \\
\hline$>=3$ & 21 & $11.7 \%$ \\
\hline
\end{tabular}

Table 3 shows that there were 4 (2.2\%) females who were unmarried in the study rest all were married 176 $(97.7 \%)$. In this study authors found that nulliparous women, para 1 and para 2 all were almost in comparable proportion being 48 (26.7\%), $56(31.1 \%)$ and $55(30.6 \%)$ respectively.

Table 4: Indication of abortions.

\begin{tabular}{|lll|}
\hline Indications & $\mathbf{n = 1 8 0}$ & $\mathbf{\%}$ \\
\hline Maternal risk (A) & 18 & $10 \%$ \\
\hline Rape (B) & 03 & $1.7 \%$ \\
\hline Congenital anomaly (C) & 82 & $45.6 \%$ \\
\hline Failure of contraception (D) & 77 & $42.8 \%$ \\
\hline
\end{tabular}

Indications for abortions were recorded at the time of admission as per the MTP Act and divided in categories mentioned in Table 4. Congenital anomaly (C) was the leading indication behind $82(45.6 \%)$ patients opting for terminations. Seventy-seven $(42.8 \%)$ patients had abortions for failure of contraception. Eighteen (10\%) abortions were done for maternal health risks and 3 (1.7\%) patients had pregnancy as a result of rape and hence aborted.

For those patients who wanted abortions for failure of contraception, 46 (59.7\%), were not able to afford birth 
of another child. Nineteen (24.67\%) patients learned about their pregnancy by second trimester, $5(6.5 \%)$ patients entered second trimester due to indecisiveness, 3 $(3.89 \%)$ patients all coming from hilly areas missed the opportunity to get first trimester abortions (Table 5).

Table 5: Reasons for termination of unplanned pregnancy.

\begin{tabular}{|lll|}
\hline Reasons & $\mathbf{n = 7 7}$ & $\%$ \\
\hline Late diagnosis & 19 & $24.67 \%$ \\
\hline Late decision & 05 & $6.49 \%$ \\
\hline Peer pressure & 04 & $5.19 \%$ \\
\hline Non affordability & 46 & $59.74 \%$ \\
\hline Logistic problems & 03 & $3.89 \%$ \\
\hline
\end{tabular}

Table 6: Induction-abortion interval.

\begin{tabular}{|lll|}
\hline $\begin{array}{l}\text { Induction- abortion } \\
\text { Interval (hours) }\end{array}$ & $\mathbf{n = 1 7 9}$ & $\mathbf{\%}$ \\
\hline$<24$ & 70 & $39.1 \%$ \\
\hline $24-48$ & 58 & $32.4 \%$ \\
\hline $48-72$ & 37 & $20.7 \%$ \\
\hline$>72$ & 14 & $7.8 \%$ \\
\hline
\end{tabular}

On day 1 , tablet mifepristone $200 \mathrm{mg}$ was given orally and after 48 hours tablet misoprostol $400 \mathrm{mcg}$ per vaginally was given which was repeated 4 hours (maximum dose-2000 $\mathrm{mcg}$ ) till expulsion of abortus. Table-6 shows that, 37 (20.7\%) patients expelled in less than 24 hours of tablet mifepristone.

Among total of 180 patients $179(99.4 \%)$ patients had aborted and one patient had emergency hysterectomy due to undiagnosed adherent placenta and no mortality documented. A total of $70(39.1 \%)$ patients required 48 72 hours from induction to abortion. Total of $14(7.8 \%)$ patients required more than 72 hours from the start of induction.

Table 7: Methods of contraception.

\begin{tabular}{|lll|}
\hline Methods & $\mathbf{n}$ & $\%$ \\
\hline Barrier & 45 & $25 \%$ \\
\hline COCP & 82 & $45.6 \%$ \\
\hline DMPA & 27 & $15 \%$ \\
\hline IUCD & 03 & $1.7 \%$ \\
\hline Tubal ligation & 22 & $12.2 \%$ \\
\hline $\begin{array}{l}\text { Emergency hysterectomy } \\
\text { (undiagnosed adherent placenta) }\end{array}$ & 01 & $0.6 \%$ \\
\hline
\end{tabular}

All patients were offered contraception before discharge (Table 7). Among all patients, 82 (45.6\%) patients accepted COCP, barrier contraception was the choice for $45(25 \%)$ patients.

Injectable contraception DMPA was accepted by 27 (15\%) patients while $22(12.2 \%)$ patients opted for tubal sterilization.

\section{DISCUSSION}

Studies exclusively on second trimester induced abortions are scanty all over the world. A combined study done by Guttmacher Institute, IIPS Mumbai and the population council Delhi estimated 15.6 million abortions annually in 2015 in India. This translates to an abortion rate of 47 per 1000 women in age group of 15-49 years which is similar to abortion rates in neighboring south Asian countries. $^{2}$ In 1996 a study in rural Maharashtra reported an incidence of $26 \%$ while the study conducted in Amhara region of Ethiopia in Africa reported an incidence of $19.2 \% .^{3,4}$ During the study period of 6 years, 14251 total live births occurred in our Institute and total number of induced abortion during this period were. This study found an incidence of 12.6 second trimester induced abortions per 1000 live births.

Eighty percent of patient in this study were between 2035 years of age which is the period of maximum sexual activity and child births in Indian females. Out of them $69(38.3 \%)$ were in 25-30 year of age. Study by Mulat A et al reported that maximum number of females was in age group of $20-24$ years $(33.9 \%)$ while $65.4 \%$ were in the age group of $25-35 \%$ and $24.3 \%$ were less than 20 years while in this study they were $3.3 \%$. This emphasizes the need of comprehensive and safe abortion and contraception care in society.

In this study, Hindu were $85 \%$ while Muslims were $8.9 \%$ who opted for abortions. A study conducted by Aggarwal $\mathrm{P}$ et al, reported $86.9 \%$ of Hindus and $11.9 \%$ of Muslims which is comparable to this study..$^{5}$ The difference in numbers among different religions of India is due to diversity of religious beliefs prevalent in India. There were no Christians and Sikh community patients however other religion (Buddhism, Jain etc.) were $1.7 \%$. In a study done by Aras RY et al reported that among married and unmarried abortion seekers, 59\% unmarried compared with $26 \%$ of their married counterpart underwent second trimester abortions. ${ }^{6}$

In our study out of 180 patients, 4 (2.2\%) were unmarried while rest were married. Out of 4 unmarried patients, 3 had pregnancy as a result of rape and were medico legal cases. For unmarried patients, late disclosure, fear of social stigma was the reason for missing the opportunity to seek first trimester MTP instead of second trimester. According to parity, 48 (26.7\%) patients were nulliparous out of them, 41 had fetal congenital anomaly incompatible with life, while 3 had abortion due to maternal health risks.

Total $82(45.6 \%)$ patients sought termination of pregnancy due to fetal congenital anomalies. 72 out of 82 patients who terminated pregnancy due to congenital anomalies were less than 35 years of age, 10 patients were above 35 years. Among them, 53.7\% patients were from Urban areas while $27.5 \%$ were from rural areas and $13.4 \%$ were from industrial areas and $9(11 \%)$ patients 
reported from hilly terrains of Uttarakhand. A study conducted by Mulat A et al reported 59.6\% second trimester abortions due to unplanned pregnancies and $31.7 \%$ abortions due to fetal anomalies. ${ }^{4}$ In this study failure of contraception was the indication for $77(42.8 \%)$ of abortions who missed the opportunity to avail comparatively safer and easier first trimester abortion. Under this $46(59.7 \%)$ patients cited non affordability of next child as reason for termination of pregnancy while $19(24.7 \%)$ came to know about their pregnancy late either due to conception during lactational amenorrhea, irregular delayed menses or pre-existing medical condition.

All patients were offered contraception after induced abortions in our institute. The study found that Combined oral contraception was accepted by $82(45.6 \%)$ patients followed by Barrier method $45(25 \%)$ and Injectable contraceptive (DMPA) $27(15 \%)$ patient as popular choices. Sterilization was done on $22(12 \%)$ patients.

IUCD was least popular as only 3 patients accepted that. Due to abnormal adherent placenta one patient required emergency hysterectomy. Kathpalia SK Brig conducted a prospective study in one of the service hospitals in India where female sterilization was accepted by $39.6 \%$ post abortion patients while Barrier method was chosen by $18.6 \%$ patients. $^{7}$

\section{CONCLUSION}

Second trimester induced abortions are still performed in large numbers in all over the country for various indications. Apart from congenital anomalies rest all indications can be reduced if women in our country are empowered to control their fertility, get education to become more aware and provided with social security.

Studies like ours might help policy makers to design policies to cater females who are missing opportunity to procure first trimester abortions and are forced to face comparatively difficult second trimester abortions
Funding: No funding sources Conflict of interest: None declared

Ethical approval: The study was approved by the Institutional Ethics Committee

\section{REFERENCES}

1. Singh S, Shekhar C, Acharya R, Moore AM, Stillman M, Pradhan MR, et al. The incidence of abortion and unintended pregnancy in India, 2015. Lancet Glob Health. 2018;6(1):e111-20.

2. Stillman M, Frost JJ, Singh S, Moore AM, Kalyanwala S. Abortion in India: a literature review. New York: Guttmacher Institute; 2014:12-14.

3. Zavier AF, Jejeebhoy S, Kalyanwala S. Factors associated with second trimester abortion in rural Maharashtra and Rajasthan, India. Glob Pub Health. 2012;7(8):897-908.

4. Mulat A, Bayu H, Mellie H, Alemu A. Induced second trimester abortion and associated factors in Amhara region referral hospitals. Biomed Res Int. 2015;2015.

5. Aggarwal P, Agarwal P, Zutshi V, Batra S. Do women presenting for first and second-trimester abortion differ socio-demographically? Ann Med Health Sci Res. 2013;3(2):187.

6. Aras RY, Pai NP, Jain SG. Termination of pregnancy in adolscents, J Postgrad Med. 1987;33(3):120-4.

7. Kathpalia SK. Acceptance of family planning methods by induced abortion seekers: An observational study over five years. Med J Arm Forces India. 2016;72(1):8-11.

Cite this article as: Nimonkar $\mathrm{S}$, Chaudhari $\mathrm{P}$, Gupta V, Saxena N, Agarwal S. Factors associated with induced second trimester abortion at a tertiary level hospital of Uttarakhand region: a 6-year retrospective study. Int J Reprod Contracept Obstet Gynecol 2020;9:2333-6. 